\section{Seal hunting is no joking matter}

SIR - A feature of the anti-sealing lobby that struck me from the outset (1965) as ominous was their use of the techniques so well described in Animal Farm. They have succeeded in persuading a very large number of people to see the issues in their own simplistic way. I find it incredible, however, that a scientific journal should print a political cartoon of the type seen in Nature of 23/30 December 1982 (p.674).

The early settlers of N.E. Newfoundland were faced with a severe continental climate bringing pack ice to the region for 5 months and making fishing impossible. Winters were passed in idleness until it was found that harp seals could be netted to provide oil, leather and meat, with the much later addition of fine furs. Alone among east coast Canadian fishing regions the inshore fishery of Newfoundland remains depressed due to excessive manpower and lack of alternative employment; sealing remains a valuable source of additional income. It is not generally understood that the winter inshore "fisheries" for harp seals off the Canadian east coast are diverse, taking various age categories between December and May. Thus a shift from a whitecoat hunt to the taking of other pelt types, if aesthetically desirable, would require no more than the intensification of an existing trend away from the use of large vessels to the seasonal use for sealing of mediumsized fishing vessels (longliners).

Further north in Labrador, a true arctic economy is practised by the Inuit or Eskimo (including Greenlanders) where sealing becomes the dominant source of income based on a renewable resource. The result of the propaganda aimed at eastern Canadian and other harp seal hunting has been to depress the prices of all hair seal pelts, such that the incomes of at least 100,000 people have been seriously jeopardized.

Part of the now popular simplistic approach to exploitation of seals and whales is to believe that once "victory" is achieved in legislating an end to hunting or buying, the problem is solved. However, the issues of sealing and whaling will always remain with us. First, the animals reproduce and grow slowly and so cannot be reared. Second, their pelagic populations do not compete with man for space, so that their habitats remain intact, as long as we maintain their food base, and the water quality of the near-seas. Consequently when hunting pressure is relaxed, sea mammal populations rise to near primaeval levels, as we can now observe for many whale and seal populations around North America, and for grey seals around the United Kingdom. By contrast, wild ungulate populations on land - the closest parallel in terms of biomass - must be conserved also by safeguarding habitat or by domestication.
If therefore we are now passing through a period when whaling and sealing are sociably unacceptable we ought to be working hard at two prerequisites of future exploitation: proper understanding of population dynamics and satisfactory methods of humane killing. Initiatives such as the Canadian government's proposal to examine North Atlantic sealing, together with the existing structure of the International Whaling Commission, provides a suitable framework for the first. Work on humane killing of seals and whales has been, by contrast, intermittent and underfinanced.

\section{Fisheries and Oceans Canada,} Arctic Biological Station, Ste. Anne de Bellevue, Québec, Canada

\section{Botany leader}

SIR - In the news item "US universities: Biological sciences ranked" (Nature 20 January, p.189) the statement is made that "In botany, the best were UC Davis and Vanderbilt". That should have been UC Davis and the University of Texas at Austin. While the error is understandable since it is easy to misread the listings, we worked too long and too hard to reach this ranking not to ask for a correction.

TOM J. MABRY

Department of Botany, University of Texas at Austin, Austin, Texas, USA

\section{Stamp watching}

SIR - In their interesting essay "Stamp watching and bird collecting"' (ref.1) Robert and Judith May made one error so blatant that perhaps it was intentional - like their title. They expressed surprise that the number of bird species in North America and Britain "is almost exactly what would be expected from the MacArthur-Wilson species-area relation, $S \sim A^{z}$," because "the underlying premises from which the species-area relation is deduced pertain more to archipelagoes of islands than to large continental masses".

This misconception arises from a lack of historical perspective. The species-area relation is Arrhenius' law, $N=k A^{z}$, developed from botanical sampling ${ }^{2}$. It seems applicable to most collections (even of stamps!) in both space and time and was extended in Preston's classic paper ${ }^{3}$ to the biota of continents and islands. MacArthur and Wilson ${ }^{4}$ contributed an hypothesis to explain the relationship as it applied to islands - the number of species being a balance between rates of migration and extinction - but even this is merely a special case of the balance between species differentiation and extinction discussed by Preston for continents.

Indeed it is curious that "Many, if not most, of the subject's leading theoreticians in this century - Mayr, Lack, MacArthur and others - have been 'bird people'". Preston is too.

Ecology Division, DSIR, JOHN E.C. FLUX Lower Hutt, New Zealand

1. May, R.M. \& May, J. Nature 299, 11 (1982)

2. Preston, F.W. Ecology 41, 611-627 (1960).

3. Preston, F.W. Ecology 43, 185-215, 410-432 (1962)

4. MacArthur, R.H. \& Wilson, E.O. Evolution 17, 373-387 (1963).

\section{South Indian names}

SIR - J.A. Irving (Nature 16 September 1982, p.200) states that Chinese surnames precede given names unlike Western conventions. This practice exists amongst the South Indians too. Like the Chinese, some of those who study in the West reverse this order while most don't, initializing the surname and the middle name. Thus S.N. Bose (of Bose-Einstein statistics), a Bengalee, follows the common Western and North Indian custom while C.V. Raman (of the Raman effect), a South Indian, has as his given name V. Raman and surname initialized to $C$.

The way the surnames are derived is different in the four South Indian states. The Andhras and the Kannadigas (of Andhra Pradesh and Karnataka) derive their family name through the paternal line, all generations having the same family name. The Tamilians (of Tamilnadu) have as their surname their father's given name with no constant family name. The Malayalees (of the state of Kerala) have two family names, one from the paternal line and the other from the maternal line, the males carrying the constant paternal family name and the females carrying the constant maternal name.

Since all computer forms now require names in the sequence last, first, middle perhaps the Western convention is on its way to change.

M.V. RAMANA

Department of Physics,

West Virginia University,

Morgantown, West Virginia, USA

\section{Hopeful thinking}

SIR - I do not wish to deter Mr Lawden from his desire to preserve the meaning of words. However, it is obvious from his letter (Nature 6 January, p.9) that it is too late to preserve the meaning of the word "hopefully".

D. L. SIMMS

Department of the Environment,

London SWI, UK 